\title{
An Uncommon Diagnostic Algorithm for a Common Condition
}

\author{
Marco Luigetti ${ }^{1}$, Natalino Palermo ${ }^{2}$ and Enrico Nista ${ }^{3}$
}

Key words: brain CT, earwax, dizziness, emergency

(Intern Med 54: 1679, 2015)

(DOI: 10.2169/internalmedicine.54.4529)

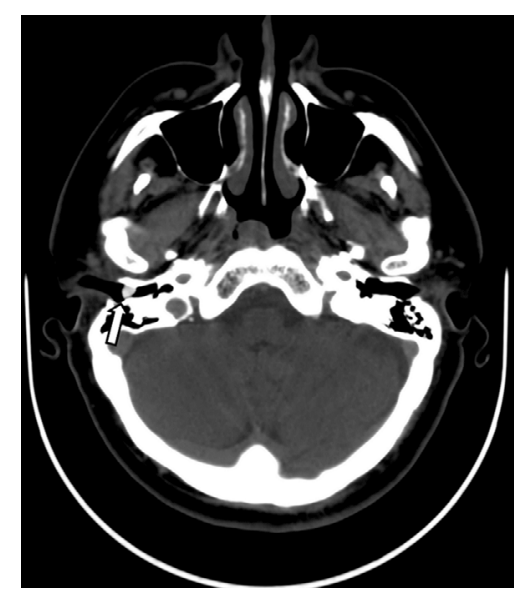

Picture. in the right ear (arrow in Picture). An evaluation by an otorhinolaryngologist confirmed this finding, and proper therapy for earwax removal was suggested.

In the emergency department, radiological examinations often precede clinical evaluations by specialists in order to save time and more promptly reach the correct diagnosis $(1,2)$. However, in some cases, as in the present case, allowing for a clinical evaluation by a specialist prior to the radiological investigations may yield the correct diagnosis, thus saving costs for the healthcare system and preventing radiation exposure to the patient $(1,2)$.

The authors state that they have no Conflict of Interest (COI).

\section{References}

A 62-year-old man presented to our emergency department with a history of dizziness lasting for three weeks. He had no significant past illnesses and took no medications. A neurological examination was unremarkable. An urgent brain CT scan was performed to exclude the possibility of stroke or neoplasia; however, it revealed only cerumen impaction
1. New study: CT a poor tool for patients presenting with dizziness. ED Manag 25: 114-117, 2013.

2. Saber Tehrani AS, Coughlan D, Hsieh YH, et al. Rising annual costs of dizziness presentations to U.S. emergency departments. Acad Emerg Med 20: 689-696, 2013.

\footnotetext{
${ }^{1}$ Department of Geriatrics, Neurosciences and Orthopedics, Institute of Neurology, Catholic University of Sacred Heart-Rome, Italy, ${ }^{2}$ Nursing Service, Catholic University of Sacred Heart-Rome, Italy and ${ }^{3}$ Emergency Department, Catholic University of Sacred Heart-Rome, Italy Received for publication November 17, 2014; Accepted for publication November 19, 2014 Correspondence to Dr. Marco Luigetti, mluigetti@gmail.com

(C) 2015 The Japanese Society of Internal Medicine Journal Website: http://www.naika.or.jp/imonline/index.html
} 